\section{Core correlations}

\section{Rainer Zahn}

THE past two years have seen a revolution in our thinking on climate variability, largely because of the signs of ultra-fast climate oscillations found in deep ice cores. But the ice-core records for part of the last interglacial period disagree, and other evidence for the variability of the climate during this period has been eagerly sought - after all, it might be a model for our own interglacial. On pages 323 and 326 of this issue, Keigwin et al. ${ }^{1}$ and McManus et al ${ }^{2}$ provide welcome evidence for how far oceanic records from the same period correlate with the ice- core data.

The story begins in September 1992, when the first results to emerge from the Greenland Ice-Core Project (GRIP), one of two international teams drilling at Summit in Greenland, indicated that the last glacial period had been punctuated by surprisingly warm intervals ${ }^{3}$. Within months, results from the nearby GISP2 core $^{4}$ had confirmed this and shown that ultra-fast, high-amplitude climate 'flickers' were common in the glacial periods. So a vigorous search started among marine palaeoclimatologists and mod- ellers for clues to how the oceans' circulation might have contributed to these climatic lapses.

In September last year, Bond et al. ${ }^{6}$ obtained high-resolution records of planktonic foraminifera abundances from a North Atlantic sediment core, and found that these were a near-perfect match with the ice-core records over the past 90,000 years (back through the last glacial period, but not the previous interglacial). The foraminifera abundances vary according to ocean surface temperature, so this provided part of the urgently sought link with the North Atlantic's thermohaline circulation. Bond et al. suggested that glacial climates were repeatedly perturbed by collapses of the North American ice sheet: huge iceberg surges flooded

\title{
Linking ice-core records to ocean circulation
}

Shown here are the positions of the Greenland 'Summit' ice cores (labelled 1) and the sediment cores used by Keigwin et al. ${ }^{1}(4)$ and McManus et al. ${ }^{2}$ (2 and 3 ) on pages 323 and 326 of this issue to monitor the North Atlantic's circulation during the last interglacial. The North Atlantic polar front (the circulation boundary between cold polar and warm boreal water masses) may be viewed as a door which opens and shuts in the course of climate shifts between interglacial and glacial conditions.

For our present age, the Holocene (left), the ice-core record implies a stable interglacial mode with no major per. turbations ( $\mathrm{BP}$, before present). The 'door' in the North Atlantic is wide open and allows warm subtropical water masses to flow far to the north, thus driving the thermohaline circulation and heating up
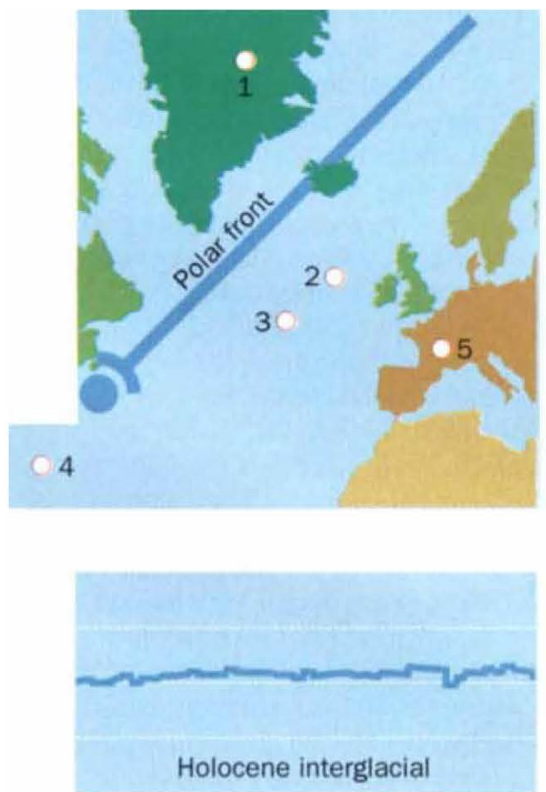

Modern

10,000 yr BP most of northwestern Europe.

During the last glacial period (centre), the 'door' was shut. Warm waters did not penetrate to the north, so the North Atlantic region cooled and continental ice sheets grew. The North Atlantic's thermohaline circulation was much weaker than today. The ice-core record for this period shows rapid climate oscillations thought to be linked to iceberg surges (triangles) coming from the North American 'Laurentide' ice sheet Quasi-periodic ice-sheet collapses resulted in alternating maximum and minimum rates of iceberg and meltwater discharge to the North Atlantic ${ }^{6}$, which destabilized the glacial mode of circula. tion to the extent that the polar front door opened, producing intermittent spurts of enhanced thermohaline circulation.

For the peak-interglacial Eemian

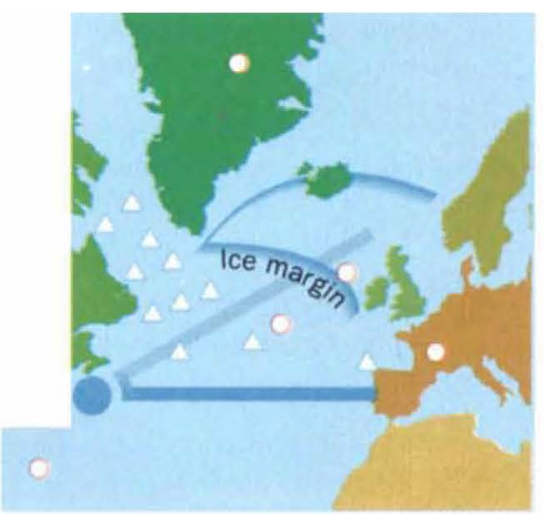

period (right), the record from the Greenland Ice-core Project GRIP, though not from the sister core GISP2, implies largescale and rapid climate oscillations. If the North Atlantic's thermohaline cir. culation was involved, this would imply rapid retreats and advances of polar water masses which would have resulted in fast shifts of the polar front. The new marine records ${ }^{1,2}$ imply that this conceptual model may hold for the wider interglacial stage 5 . For the peak interglacial Eemian, they suggest rather that surface water conditions and deep-water flow in the North Atlantic were stable; but largescale fluctuations in the Eemian section of a terrestrial pollen record (ref. 9; labelled 5) might be the elusive terrestrial analogues of the climate instabilities seen in the Greenland ice-core record.

R. Z.
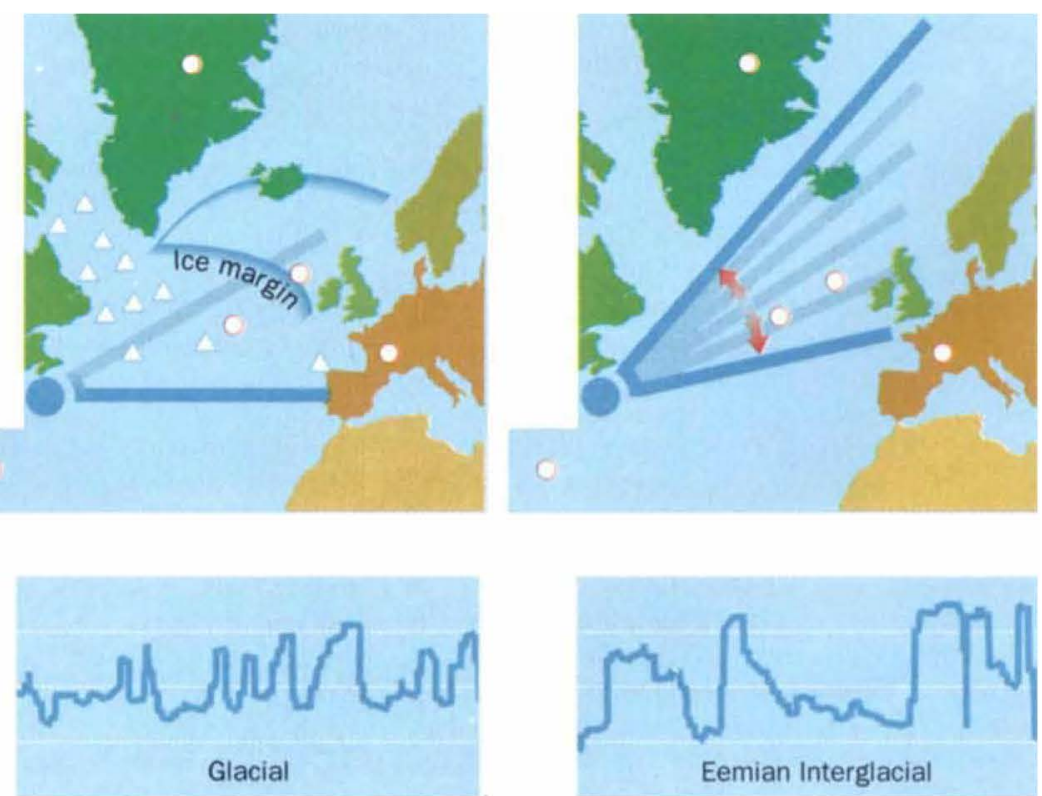

20,000 yr BP 
the North Atlantic during the early phase of ice-sheet collapse, whereas in the later stages when the ice margin had retreated further inland, iceberg and meltwater discharge ceased, thus allowing in its place an enhanced inflow of warm, salty subtropical waters.

This elegant concept neatly explained the early evidence from the ice cores. But meanwhile, the GRIP members had drilled deeper and published some still more disturbing news ${ }^{7,8}$. During the last interglacial, in the period known as the Eemian, when there were no great ice sheets around, climate instabilities appeared to have occurred which were at least as strong as those reported for the glacial period. This time, though, the GISP2 record contradicted the GRIP results ${ }^{5}$, and doubts arose as to whether the Eemian section of the GRIP core was distorted by anisotropic shear caused by ice-sheet flow.

One thing seems certain: if the GRIP ice-core record is correct, the Eemian climate jumps should have left their imprint in other climate records such as marine sediment cores. Both Keigwin et al. and McManus et al. have looked at deep-sea sediment cores drilled in the North Atlantic, concentrating on what they could tell us about climate during the last interglacial period (marine isotope stage 5, 135,000-65,000 years ago). This interglacial was punctuated by two colder 'stadials' when there was more continental ice, and three 'warmer' interstadials when there was less. The warmest of these, about 120,000 years ago, was the Eemian.

But the specific aims of the two groups were rather different. Keigwin et al. ${ }^{1}$ use records of carbonate content and carbon isotopes which are indirectly linked to the deep ocean's chemistry rather than to surface conditions. These provide proxies for the rates at which deep waters are formed at high latitudes and are being pumped through the North Atlantic. Significant variability is seen in the records, suggesting that deep-water circulation was highly variable throughout the last interglacial isotope stage 5 . This picture is corroborated by the data provided by McManus et al. ${ }^{2}$, who extend records of abundances of polar planktonic foraminifera (marine microorganisms which live close to the sea surface) back much further than those of Bond et al. They show that surface water variability in the subpolar North Atlantic was equally high in response to retreats and re-advances of polar waters.

Within the limitations of the age models for the sedimentary records, the surface and deep-water profiles generally correlate with the climate profiles from the Greenland ice cores. So it seems that the conceptual model of a close link between the North Atlantic's thermohaline circulation and climate variability applies also for the wider interglacial stage 5. But for the Eemian peak-interglacial period (isotope sub-stage 5e), neither data set shows anything like the variability we would expect from that seen in the Eemian section of the GRIP ice-core record. The records from the subpolar North Atlantic which are closest to the Greenland ice sheet are smooth and stable, and those from the subtropical North Atlantic show no more variability than is seen in other marine records throughout the world ocean. One may argue that, as at present, the Eemian ice sheets were simply too small to trigger occasional iceberg surges and meltwater discharge, thus making climates in the North Atlantic region stable.

The work of both Keigwin et al. and McManus et al. supports this intuitive argument, in that the surface and deepwater variability seen in their records starts immediately after the Eemian peakinterglacial. This was when larger volumes of continental ice first began to accumulate in high latitudes even though climate conditions were still in an interglacial mode. Keigwin et al. have in fact compiled terrestrial palaeoclimate data which indicate that post-Eemian continental climates as far south as California responded to the brief convulsions of the North Atlantic traced in their data. During the Eemian peak-interglacial, however, none of the terrestrial records shows climate signals comparable to the ice-core signals.

With these data, it might seem that the book is closed on Eemian climate instabilities. But there is an intriguing footnote to the story. In Central Europe, a French team believes it has indeed found evidence for Eemian climate instabilities. Thouveny et $a l{ }^{9}$ have obtained pollen records of climate from lakes in France which reveal an astonishing similarity both in structure and timing to the GRIP ice-core record. Details will be revealed in a forthcoming issue of Nature; but terrestrial palaeoclimatologists may have an ace up their sleeve with which to solve the current stalemate between the marine and ice-core teams. It may well be that for some reason the Eemian climate jumps left the marine system in the North Atlantic region untouched, thus handing the book over to the terrestrial community to advance our understanding of the nonconservative behaviour of our climate system.

Rainer Zahn is at GEOMAR, Research Center for Marine Geosciences, Kiel University. D-24148 Kiel, Germany.

\footnotetext{
1. Keigwin, L. D.. Curry, W. B., Lehman, S. J. \& Johnsen, S. Nature 371, 323-326 (1994)

2. McManus, J. F. et al. Nature 371, 326-329 (1994)

3. Johnsen, S. J. et al Nature 359, 311-313(1992).

4. Taylor, K. C. et al Nature 361, 432-436 (1993).

5. Grootes, P. M. et al. Nature 366, 552-554 (1993)

5. Grootes, P. M. etal. Nature 366, 552-554 (1993)

7. GRIP members Nature 364, 203-207 (1993).

7. GRIP members Nature 364, 203-207 (1993).

9. Thouveny, N. eta!. Nature (in the press)
}

\section{Plane with fire}

EVERY solid surface exposed to air acquires a monolayer of gas molecules, including those of oxygen. Charcoal can absorb enough oxygen to ignite spontaneously. Charcoal saturated by oxygen can even be exploded. Daedalus has been generalizing from these facts. He reckons that on a smooth combustible surface with an oxygen monolayer, a novel 'surface explosion' could be transmitted: the burning of surface molecules in that monolayer. Once initiated, it should flash over the surface with a feeble bang.

Such a blast would be propagated by Rayleigh surface waves. The burning of a single monolayer provides only limited energy, but since the resulting shock can spread out in just two dimensions it should still have ample power density to keep itself going. The small release of heat would be absorbed almost instantly by the bulk material

Most plastics, and indeed all hard combustible materials that adsorb oxygen, should be surface-explosive. They could be set off by an intense local laser pulse, coupled with a sideways kick from a powerful piezoelectric transducer. There will be a surface flash and a weak bang. A millisecond or so later, the surface would have taken up another monolayer of oxygen and could explode again.

The repeated explosion of a surface could make a novel stroboscopic lamp. It would also be the ultimate in precision machining. A plastic lens or mirror could be precisely shaped by the explosion of successive monolayers of its substance. With a cylindrical workpiece, the explosion might even run continuously round it, lathe fashion, generating a loud howl at its rotation frequency.

Surface explosions may, however, be most useful as cleaning agents. Debris, dust and bacteria would literally be blown away, and possibly burnt up in the process; the surface would be cleaned and sterilized instantly. Better still, the surface need not be tidied first. Objects resting on a surface seldom displace the oxygen monolayer, so the explosion would travel beneath them. Hospital surfaces, kitchen tables with food still on them, grimy painted walls, bookshelves loaded with books, all could be intimately and instantly cleaned for the loss of one monolayer of their substance. Daedalus even began to dream up a human instantcleaning process. One bang, and you would be tingling-clean from top to toe without even taking off your clothes. Sadly, human skin is too soft and lossy for a surface explosion to propagate. Soap and water will be with us for a while yet. David Jones 